\title{
Vegetation responses to integrated water management in the Ejina basin, northwest China
}

\author{
Yichi Zhang, ${ }^{1}$ Jingjie Yu, ${ }^{1 *}$ Ping Wang ${ }^{1}$ and Guobin $\mathrm{Fu}^{2}$ \\ ${ }^{1}$ Key Laboratory of Water Cycle \& Related Land Surface Processes, Institute of Geographical Science and Natural Resources Research, Chinese \\ Academy of Sciences, 11A, Datun Road, Chaoyang District, Beijing 100101, P. R. China \\ ${ }^{2}$ CSIRO Land and Water, Private Bag 5, Wembley, WA 6913, Australia
}

\begin{abstract}
:
The Ejina basin, which is located in arid and semi-arid areas of northwest China, has experienced severe environmental deterioration in the past several decades, and an exploratory project was launched by the Chinese Government in 2001 to restore this degraded ecosystem. In this study, multi-scale remotely sensed data and field investigations were used to quantify the responses of vegetation to the implementation of integrated water management under this project. In terms of the seasonal accumulated Normalized Difference Vegetation Index (SAN) variation, (1) the vegetation in $80 \cdot 4 \%$ of the oasis regions showed an increasing or recovering trend, and increasing SAN trends with a magnitude greater than $0.14 \mathrm{a}^{-1}$ mainly resulted from cultivated land reclamation; (2) the vegetation in $91.5 \%$ of the desert regions presented an increasing trend, and the statistically significant trends mainly appeared in the middle and lower Ejina basin; (3) the vegetation in $19.6 \%$ of oasis and $5 \cdot 1 \%$ of desert regions showed a decreasing or degrading trend, mainly where rivers diminished and along artificial concrete canals; and (4) opposite signs of vegetation trends occurred simultaneously along some natural rivers experiencing water reduction, with a decreasing trend generally appearing in the high SAN regions, whereas an increasing trend was seen in the low SAN regions. The broad vegetation recovery observed was due to the comprehensive improvement of the water environment, which was attributed to both the increase in runoff entering the Ejina basin and the adoption of engineering measures. Vegetation degradation in the area mainly resulted from deterioration of the local water environment, which was closely related to the problems of water management. The results of this study can be used as a reference for adjusting the current water resource management strategy to effectively restore this ecosystem. Copyright $($ C 2011 John Wiley \& Sons, Ltd.
\end{abstract}

KEY WORDS vegetation response; integrated water management; remote sensing; Ejina basin; Heihe basin

Received 18 June 2010; Accepted 24 February 2011

\section{INTRODUCTION}

China's northwestern arid region is characterized by topography of alternating mountains and plains. The mountains encircle large plains, dividing the arid area into several interior basins, including the Tarim basin and the Heihe basin. Because the mountains can intercept a great deal of water vapour and form precipitation, runoff is mostly generated in mountainous areas, which are usually found in the upper basins; it is rarely generated over plains with an extremely arid climate, which cover the middle and lower basins. The rivers in the region originate from mountains, and the groundwater recharged from these rivers represents almost the only water source for social-economic development and ecosystem maintenance on the plains. This basic hydrological characteristic determines the natural vegetation in the arid northwest of China, which is mainly distributed along rivers or where the groundwater maintains a proper level and salinity. With the increases in land and water resource exploitation that have occurred since the 1950s, the plains have

* Correspondence to: Jingjie Yu, Key Laboratory of Water Cycle \& Related Land Surface Processes, Institute of Geographical Science and Natural Resources Research, Chinese Academy of Sciences, 11A, Datun Road, Chaoyang District, Beijing 100101, P. R. China.

E-mail: yujj@igsnrr.ac.cn faced serious environmental deterioration and ecosystem degradation, including the drying up of rivers and lakes, declines in the groundwater level, and desertification, which has been especially remarkable in the lower basins (Feng and Cheng, 1998; Wang and Cheng, 1999; Chen et al., 2010). To restore these ecosystems, exploratory measures have been successively undertaken in these basins in the last decade. Comprehensive evaluations of the vegetation responses to these measures are vital for providing scientifically and technically sound suggestions to maintain the health of the ecosystem and the proper functioning of the river.

The Heihe basin is the second largest arid interior basin in China, and serious ecological and environmental problems have been reported in its lower basin, the Ejina basin (Feng et al., 2004; Qi and Luo, 2005; Wang et al., 2004; Zhang et al., 2005; Ji et al., 2006; Xi et al., 2009; Zhu et al., 2009). The oasis in the Ejina basin separates the deserts of Xinjiang and Inner Mongolia and plays a barrier role in preventing dust storms from invading the north China. However, with the degradation of the natural vegetation and desertification of the land in the Ejina basin, it has become a source of dust storms. This situation not only dramatically increased the number of dust storms in local region but also resulted in greater numbers of dust 
storms in northern China (Xu et al., 2003; Wang et al., 2004). The degradation of the natural vegetation in the region has mainly been caused by serious water shortages in the Ejina basin due to excessive water utilization in the middle Heihe basin and has been exacerbated by overgrazing and land reclamation in local areas. To restore the ecosystem, a near-term management program (NMP) was launched in the Heihe basin by the Chinese Government in 2001. Under this program, the projects aiming to retrieve the ecological environment in the Ejina basin have included the Ecological Water Conveyance Project (EWCP), the Hydraulic Engineering Project (HEP), and the Ecological Conservation Project (ECP). The EWCP guaranteed a certain volume of the streams flowing into the Ejina basin every year based on integrated ecological management in the middle Heihe basin. The HEP aimed to regulate the flow path and mainly contained river regulation projects and the construction of artificial canals and diversion projects. The ECP included a series of countermeasures, such as grazing limitation and reasonable grazing rotation, the conversion of existing grazing land and farmland into woodland or grassland, and natural vegetation conservation and irrigation. Among these projects, the EWCP, the HEP, and the natural vegetation irrigation included in the ECP constituted integrated water management measures.

Several studies have documented the vegetation changes following the progression of the NMP. For example, Jin et al. $(2008,2010)$ showed that an increasing trend of vegetation growth occurred in the lower Donghe River basin within the Ejina basin by analysing annual regional mean Normalized Difference Vegetation Index (NDVI) data from 2000 to 2006 and found that the vegetation status was highly correlated with the preceding year's runoff entering the Ejina basin. Sun and Xu (2008) reported that there were fewer Populus euphratica forests and shrubbery but more grassland in the Ejina basin in 2005 compared with 2001 using Landsat TM/ETM data. Guo et al. (2009) showed that the vegetation grew remarkably 100-400 $\mathrm{m}$ away from the water channel and around the East Juyan Lake, and the growing rates decreased with the distance from the water body based on field surveys along four transects conducted from 2001 to 2005 and around the East Juyan Lake in 2004. Guo et al. (2009) also reported a common improvement of vegetation coverage following the EWCP by comparing a TM image in 1998 with an ETM image in 2004.

These previous studies based on Landsat TM/ETM data interpretation and comparisons could only present the differences between two study dates, not the general trend or progress of the change over a longer period, and they showed the extent change of vegetation cover, not structural or function changes. In contrast, the results from field surveys or time series analysis of integrated vegetation indices can describe general trends of changes in the vegetation status, but they only provide information for sporadic positions or regional averages. However, the integrated water management measures actually altered hydrological cycle processes and resulted in spatial heterogeneity of the water environment changes in the Ejina basin. This means that the vegetation was not equally affected by the projects because the water environment represents the foundation of vegetation growth. Therefore, determining the spatial pattern of vegetation responses to these projects is essential for fully understanding the mechanisms underlying vegetation changes and accurately assessing ecosystem recovery. Unfortunately, such a study has not yet been reported in the literature, and this was the major motivation for the current study. We aimed to comprehensively assess the impact of the NMP on the ecosystem in the region in terms of vegetation change. Therefore, this study investigated the spatial pattern of vegetation change trends in the Ejina basin from 2000 to 2009 by integrating multi-temporal and multi-scale remotely sensed data from various sources and field investigations. The results of this study can be used as a reference for water resource planning and management in maintaining healthy biota and proper functioning of the river as well as promoting regional development. Our results also have potential implications for similar ecological projects in other arid interior basins.

\section{MATERIALS}

\section{Study area}

The Ejina basin is located in Inner Mongolia, northwest China, between $99^{\circ} 30^{\prime}-102^{\circ} 00^{\prime} \mathrm{E}$ and $40^{\circ} 20^{\prime}-42^{\circ} 30^{\prime} \mathrm{N}$. This region has an extreme natural environment characterized by scarce precipitation, a high pan-evaporation rate, a large diurnal temperature range, and frequent dust storms. The mean annual temperature at Ejina is $8.2^{\circ} \mathrm{C}$, with a maximum daily temperature of $41^{\circ} \mathrm{C}$ (July) and a minimum of $-36.4^{\circ} \mathrm{C}$ (January). The mean annual precipitation is only $36.6 \mathrm{~mm}$. When entering the lower basin, the Heihe River branches into two broad rivers at Langxinshan, the Donghe River and the Xihe River, which ultimately flow into the East Juyan Lake and the West Juyan Lake, respectively. These two lakes dried up in 1992 and 1961, respectively, and became the Gobi. Before entering the terminal lakes, the Donghe River and Xihe River form several tributaries, including the Nalin River, the Longzi River, and the Andu River (Figure 1). The oasis is distributed along the rivers on the alluvial fan, covering approximately $3 \times 10^{4} \mathrm{~km}^{2}$, and is encompassed by peripheral desert regions, including the Gobi and sand deserts. The population in Ejina is sparse, being composed of approximately 17240 individuals in 2007 , and the built-up town area on the oasis is concentrated over approximately $6.7 \mathrm{~km}^{2}$, or $0.08 \%$ of the study area. The predominant natural vegetation on the oasis includes $P$. euphratica, Tamarix ramosissiman, and Sophora alopecuroides. Sparse xerophil vegetation, such as Nitraria tangutorum Bobr and Haloxylon ammodendron, also exists in the desert regions. This study focused on the alluvial fan covering the entire oasis, as shown in Figure 1. 


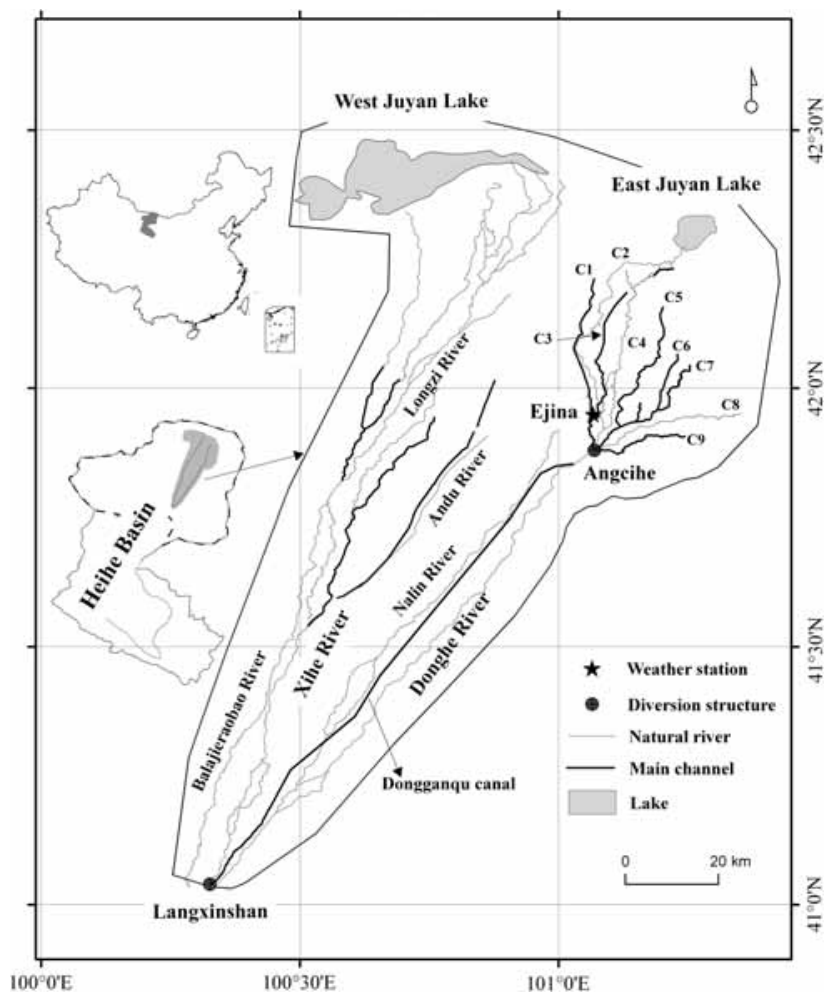

Figure 1. Location of study area and water channels

Following the implementation of the HEP, many hydraulic structures have been built in the Ejina basin, including six main canals for water conveyance, hundreds of lateral canals extending from the main canals for irrigation, and several diversion projects. Most of the main canals were built on the natural river channels, and a few are independent of natural rivers, such as the Dongganqu canal. The streamflow entering the Ejina basin was first divided into the Xihe River, the Dongganqu canal, and the Donghe River through the Langxinshan Diversion Structure; then, it runs through integrated natural-artificial water channels, such as the $\mathrm{C} 1-\mathrm{C} 9$ channels in the lower Donghe River basin (Figure 1 and Table I). Following the execution of the EWCP, the total runoff passing through the Langxinshan Diversion Structure was $52.55 \times 10^{8} \mathrm{~m}^{3}$ from 2000 to 2009 . Generally speaking, the hydrological regime has changed considerably from the regime before 2000 .

\section{Data}

The NDVI derived from satellite sensor data with a high temporal resolution has been most widely used to investigate vegetation dynamics, and it is particularly suitable for arid and semi-arid areas (McGwire et al., 2000; Chappell et al., 2001; Coppin et al., 2004; Herrmann et al., 2005; Olsson et al., 2005; Hansen et al., 2008; Jarlan et al., 2008; Neigh et al., 2008; Fabricante et al., 2009; Pouliot et al., 2009). The NDVI measures the vegetation status, including coverage and vigour, and generally, the larger the NDVI, the better the state of the vegetation. Currently, there are three long-term NDVI data sets available depending on sensor systems, which
Table I. The water channels in the lower Donghe River basin

\begin{tabular}{lllc}
\hline ID & \multicolumn{1}{c}{ Name } & Channel type & Concrete lined? \\
\hline C1 & Tiekuliganqu & Artificial canal & Y \\
C2 & Yidao River & Natural river & \\
C3 & Erdaoheganqu & Artificial canal & Y \\
C4 & Sandao River & Natural river & \\
C5 & Sidaoheganqu & Artificial canal & Y \\
C6 & Liudaoheganqu & Artificial canal & Y \\
C7 & Angcihefenganqu & Artificial canal & Y \\
C8 & Angci River & Natural river & N \\
C9 & Banbuerheganqu & Artificial canal & N \\
\hline
\end{tabular}

Table II. Landsat data used in this study

\begin{tabular}{ll}
\hline Path/row & $134 / 031$ \\
Resolution & $30 \mathrm{~m}$ \\
Acquisition & $06 / 14 / 2000 ; 08 / 20 / 2001 ; 09 / 24 / 2002 ;$ \\
$\quad$ date & $08 / 10 / 2003 ; 08 / 28 / 2004$ \\
& $09 / 13 / 2004 ; 09 / 16 / 2005 ; 09 / 19 / 2006 ;$ \\
& $08 / 21 / 2007 ; 09 / 08 / 2008$ \\
\hline
\end{tabular}

are the AVHRR NDVI, SPOT VGT and MODIS NDVI. In this study, the NDVI from the MODIS/Terra Vegetation Indices 16-Day L3 Global 250 m Grid (MOD13Q1) product during 2000-2009 was adopted as basic data and this is more useful than the other data sets. Because the remarkable vegetation changes observed in the study region mainly took place within $400 \mathrm{~m}$ of the channels (Guo et al., 2009), its 250-m resolution can capture more detailed information than the $8-\mathrm{km}$ resolution AVHRR NDVI and the $1-\mathrm{km}$ resolution SPOT VGT. The data are 16-day maximum value composites and are sufficient to eliminate the noise caused by clouds in the arid study area. The seasonal accumulated NDVI (SAN) from April to October was then used to investigate the temporal variation of the vegetation changes.

In addition to MODIS data, ten medium-resolution Landsat ETM images collected during the plant growth season from 2000 to 2008 (Table II) were also used to discriminate oasis from desert regions and to detect streamflow regimes in rivers and transient lakes located in the bottomlands where field observations were not available. These data were employed because landscape and surface water information was required to better understand the observed vegetation change and the possible reasons underlying it.

All the multi-spectral 2.4-m resolution Quickbird images available on GoogleEarth were also used in this study to obtain the distribution of cultivated lands and particular vegetation characteristics, such as type and density. Because cultivated land has higher NDVI values than other land cover types during the growing season in the study area, reclamation is expected to lead to a significant increasing trend of the SAN. If only the analysis of SAN changes is taken into account, this increasing trend is prone to be considered natural vegetation recovery or rejuvenation and restoration of the ecological environment. However, the cultivated lands in the arid area do 
not prevent sandstorms like the natural vegetation but restrained the growth of nearby natural vegetation. This is because irrigation of the cultivated lands requires the extraction of large amounts of groundwater, which will result in the groundwater level declining and the accumulation of salinity on the surface of the land. The Quickbird images used here ranged from 2002 to 2009 and covered the entire study area.

To verify the results obtained from remotely sensed data, a 30-day field investigation was conducted from July to September in 2009 covering the entire study area. For regions where continuous field observations were not available with respect to vegetation changes, especially in desert regions, qualitative vegetation change information for the past 10 years was collected through interviews with local inhabitants and government departments, such as the Water Affairs Bureau and the Forestry Bureau. Additionally, hydrological data, including the groundwater table depth, runoff, and precipitation, were used to investigate the causes of vegetation change.

\section{METHODOLOGY}

The generic approach used in this study was a pixel-based trend analysis of SAN image time series. However, there were distinct differences in the vegetation coverage, plant communities, water conditions, and the influence of the NMP in oasis and desert regions, so the first step of our analysis was to separate oasis and desert regions in the SAN images.

\section{Classification}

As the NDVI in an oasis is much higher than that in the desert during plant growth seasons, a 'critical' SAN $\left(\mathrm{SAN}_{\text {critical }}\right)$ was adopted to discriminate oasis from desert (including where it has been converted to lake later) regions in each $\mathrm{SAN}$ image. The $\mathrm{SAN}_{\text {critical }}$ was determined by comparing the SAN image with the composite image combined with the 7, 4, and 3 band of Landsat data of same year because the oasis and desert areas are distinct in the composite images. However, due to the conversion between oasis and desert during study period, the oasis and desert were not the same in all SAN images. Therefore, the study area was further classified into four classes: stable oasis regions, oasis-to-desert regions, stable desert regions and desert-to-oasis regions, according to the following procedures (Figure 2):

(1) From 2000 to 2009 , the pixels that showed SAN > $\mathrm{SAN}_{\text {critical }}$ consistently were classified as stable oasis, and the pixels that consistently presented SAN $\leq$ $\mathrm{SAN}_{\text {critical }}$ were classified as stable desert.

(2) Among the unclassified pixels in step (1), those with statistically significant increasing trends were classified as desert-to-oasis regions, and those with statistically significant decreasing trends were defined as oasis-to-desert regions.

(3) The remaining pixels fluctuated during the study period, and no statistically significant trends were found for these pixels, which could result in part from random errors in NDVI data. A simple criterion was used to separate them: those with a mean SAN value greater than $\mathrm{SAN}_{\text {critical }}$ were treated as stable oasis, and those with a mean $\mathrm{SAN}$ value less than $\mathrm{SAN}_{\text {critical }}$ were classified as stable desert.

During subsequent trend analysis, the stable oasis regions were combined with the oasis-to-desert regions as oasis regions, and the same rule was applied to the desert regions. The information on surface water and the distribution of cultivated areas were obtained directly from Landsat ETM and Quickbird images by visual interpretation, respectively.

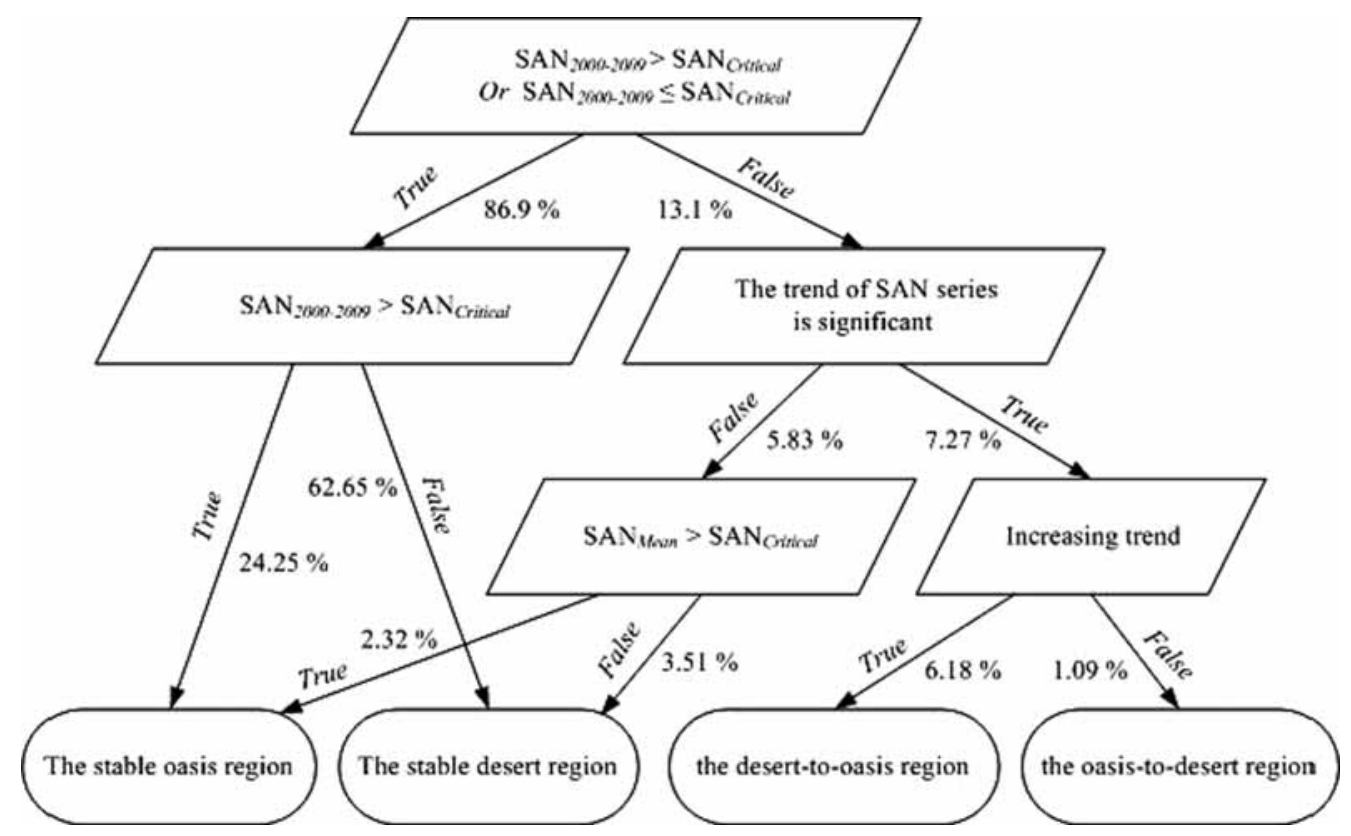

Figure 2. Classification process flow diagram 


\section{Trend analysis}

The Hirsch method (Sen, 1968; Hirsch et al., 1982; Fu et al., 2009) was used in this study to estimate the trend magnitude, $\beta$, over the 2000-2009 period for each pixel. This method is similar to the linear regression method, and $\beta$ is equivalent to the slope of a linear regression. However, this is a non-parameter method that does not require the data sample to follow a normal distribution. In this study, an increasing trend of the SAN was considered to represent vegetation recovery, whereas vegetation degradation was indicated by a decreasing trend. The larger the absolute value of the trend magnitude, $\beta$, of the SAN change, the more rapid the vegetation change. Additionally, The Mann-Kendall method (Mann, 1945; Hipel and McLeod, 2005) was used to test whether the trend was statistically significant. The significant level $\alpha=0.05$ was adopted.

\section{RESULTS AND DISCUSSION}

\section{The causative factors underlying vegetation change}

The causative factors directly influencing the vegetation change can be grouped into two categories: those related to the water environment and to human activities acting directly on vegetation (such as grazing, reclamation, and felling). Following the implementation of the ECP, grazing and felling, which directly affects the vegetation in a wide range of areas, have been effectively controlled through building fences since 2000. Subsequently, the natural vegetation change has mainly depended on the water environment, except at the specific local sites where the reclamation occurred. Precipitation, surface water, and groundwater constituted the water sources for vegetation growth. The annual precipitation at the Ejina weather station (Figure 3 ) did not show a statistically significant trend in the most recent 10 years at the $\alpha=0.05$ level based on Mann-Kendall results. Because this is the only weather station in the study region, we interviewed local inhabitants at different locations to obtain information on the climatic conditions over the past 10 years. Their experience was consistent with the weather station data, showing that there was no obvious rainfall trend in the past 10 years. Therefore, the vegetation change trend after 2000 could be considered the consequence of the surface water and groundwater environment changes

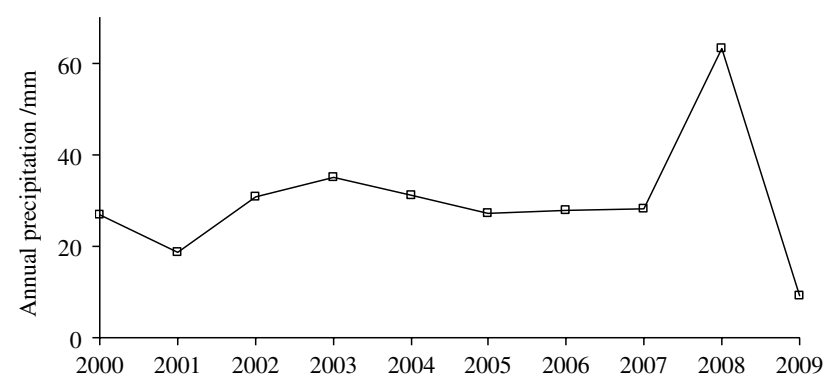

Figure 3. The precipitation measured at the Ejina weather station from 2000 to 2009 that occurred following the implementation of integrated water management measures. In the following sections, we will discuss the spatial heterogeneity of the vegetation trend based on the changes in the water environment.

\section{Distribution of the oasis and desert regions}

The $\mathrm{SAN}_{\text {critical }}$ for distinguishing oasis from desert regions was specified as $1 \cdot 0$, and the percentage of pixels for each classification is labelled in Figure 2. As shown in Figure 4, from 2000 to 2009, the stable oasis regions covered approximately $2131 \mathrm{~km}^{2}$; the oasisto-desert regions covered $87 \mathrm{~km}^{2}$; the desert-to-oasis regions represented an area of $496 \mathrm{~km}^{2}$; and the stable desert regions in study area extended over $5308 \mathrm{~km}^{2}$. Overall, the oasis area presented a $19.2 \%$ net increase from 2000 to 2009 , comprising a $4.1 \%$ conversion to desert and a $23.3 \%$ conversion from desert.

The oasis region spatially consisted of two areas, which were located along the Xihe River and the Donghe River. Several narrow strip-shaped oases within these areas formed along 5-6 relatively independent tributaries, including the Longzi River, the Andu River, and the Nalin River. These green belts showed the same northsouth direction and served as multilevel shelters against sandstorms from the northwest. A flat oasis, which was

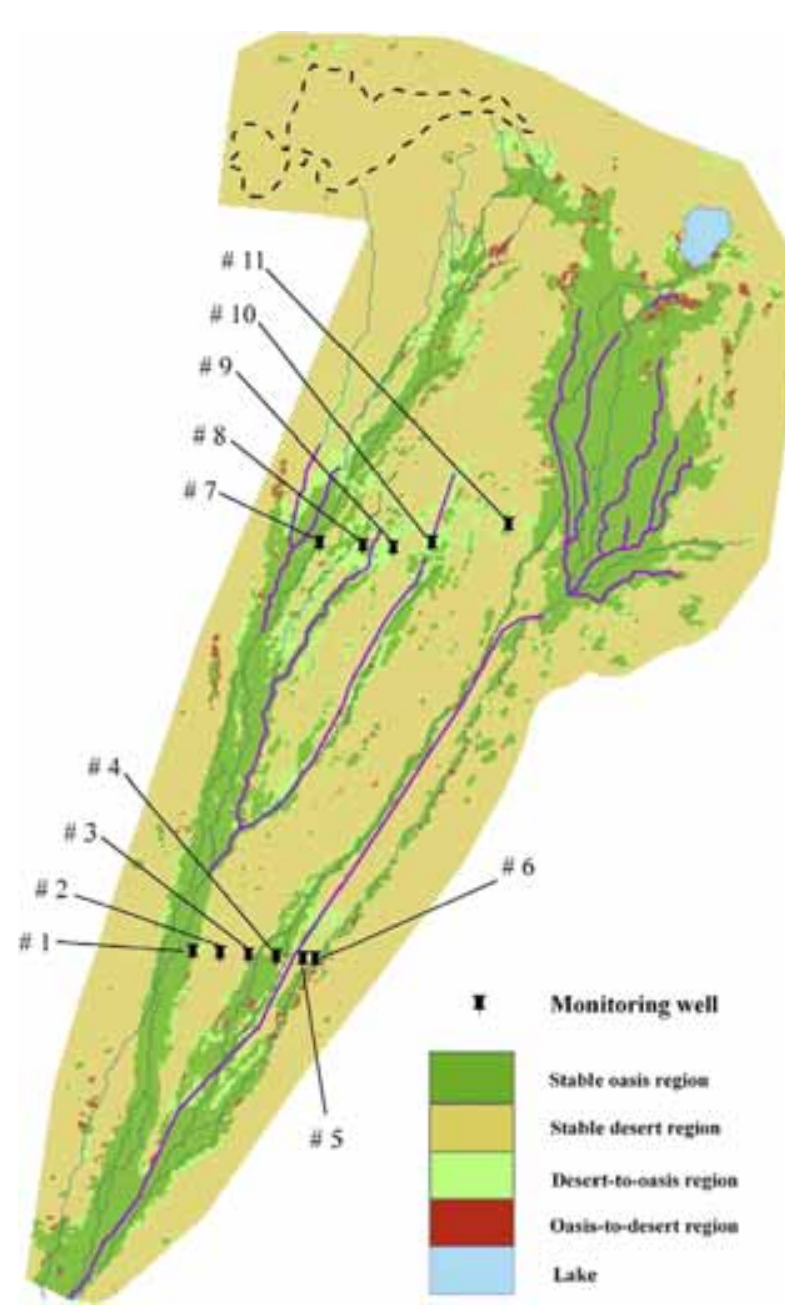

Figure 4. The spatial distribution of oasis and desert regions 
different from the strip oases in other regions of study area, formed in the lower Donghe River basin where the tributaries spread radially. The desert regions in study area consisted of $71.7 \%$ Gobi and $28.3 \%$ sandy desert. Both the oasis-to-desert regions and the desert-to-oasis regions generally appeared at the edge of the oasis.

\section{Vegetation change in oasis regions}

The oasis regions and the oasis-to-desert regions were combined as one category covering approximately $2218 \mathrm{~km}^{2}$ to investigate the vegetation trend in the oasis regions from 2000 to 2009. Along both the Xihe River and the Donghe River, the SAN showed an increasing trend in most oasis regions and a decreasing trend in few regions (Figure 5a). The areas with an increasing trend of the SAN in oasis regions included $1781.94 \mathrm{~km}^{2}$, or $80.4 \%$ of the entire oasis region, and the trends in $849.7 \mathrm{~km}^{2}$, or $38.3 \%$ of these areas were statistically significant at the $\alpha=0.05$ level, while the areas showing a decreasing trend covered $436.43 \mathrm{~km}^{2}(19.6 \%)$, and the trends in $92.4 \mathrm{~km}^{2}$, or $4.2 \%$, of these areas were statistically significant at the $\alpha=0.05$ level (Figure 5a and b). The mean trend magnitudes were 0.0431 and -0.0168 $\mathrm{a}^{-1}$ for the increasing and decreasing trend regions of the oasis, respectively (Table III). The range of the magnitude of the trend in increasing trend regions could be divided into two categories with a division of $0.14 \mathrm{a}^{-1}$. The regions with a trend magnitude greater than $0 \cdot 14 \mathrm{a}^{-1}$ had a total area of approximately $91.88 \mathrm{~km}^{2}$, representing $4.14 \%$ of the total oasis regions (Figure 6a and b). Among these areas, only those around the East Juyan Lake (approximately $2.94 \mathrm{~km}^{2}$ ) were covered by natural vegetation along all their extent, while the other areas experienced the expansion of cultivated land in the past 10 years (Figure 5a). Furthermore, the multitemporal Quickbird images showed that most of these increases in cultivated lands were due to conversion from previously derelict land, not from natural vegetation. The decreasing trend magnitude varied from -0.2449 to 0 $\mathrm{a}^{-1}$, and most regions presented a magnitude greater than $-0.05 a^{-1}$ (Table III and Figure 6b and c).

With the implementation of the EWCP, the runoff entering both the Xihe River and the Donghe River showed an increasing trend in past 10 years (Figure 7), which represented the foundation of the improvement of the water environment. Due to the runoff entering the Ejina basin remaining limited, making the rivers flow downstream as far as possible became the motivation for the implementation of the HEP. Among the engineering
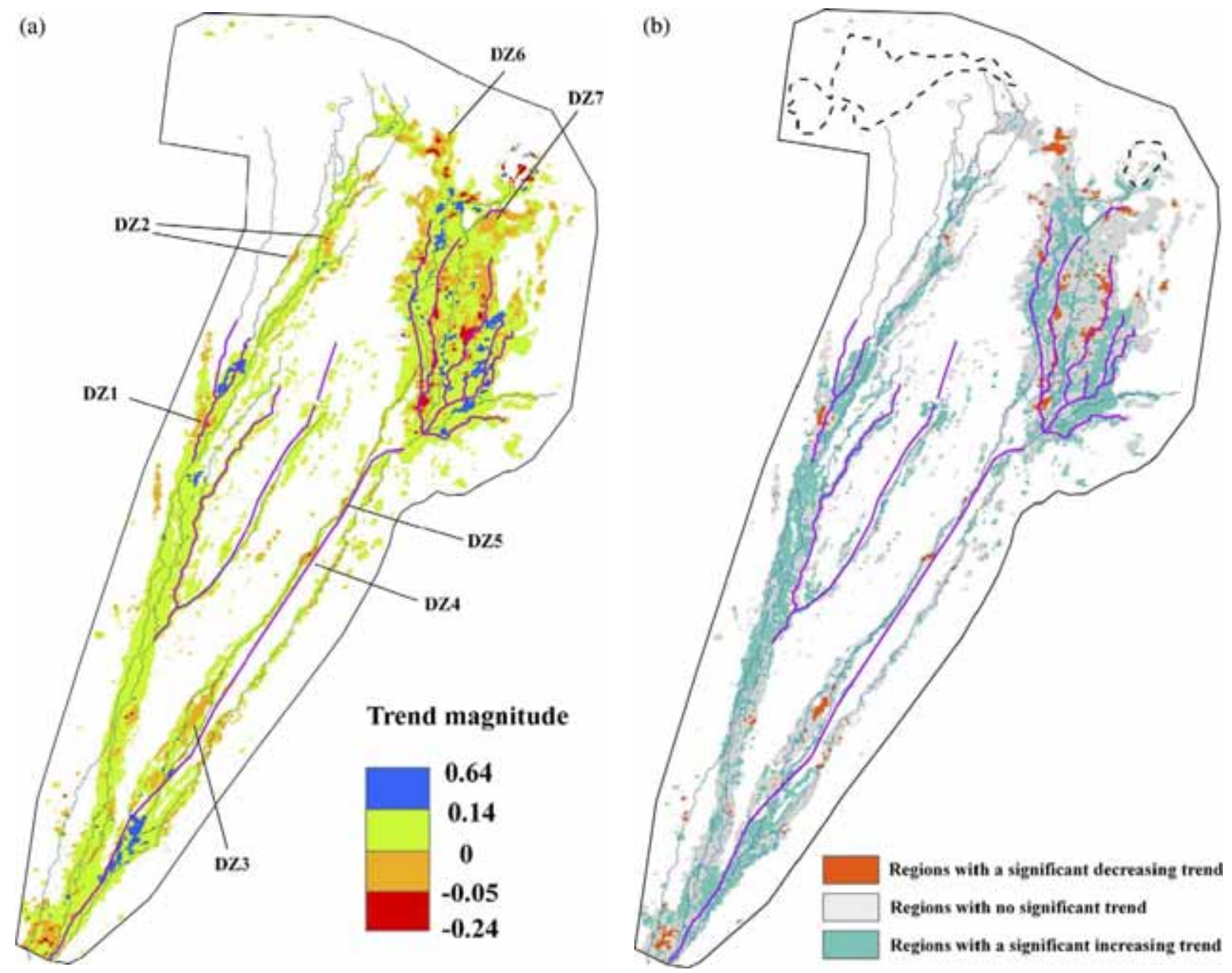

Figure 5. Vegetation trend in oasis regions: (a) spatial distribution of trend magnitude and (b) the results of significance tests at $\alpha=0.05$. (DZ, decreasing trend zone) 
Table III. Statistical analysis of trend magnitudes in different regions

\begin{tabular}{lcccc}
\hline Parameter & $\mathrm{OI}^{\mathrm{a}}$ & $\mathrm{OD}^{\mathrm{b}}$ & $\mathrm{DI}^{\mathrm{c}}$ & $\mathrm{DD}^{\mathrm{d}}$ \\
\hline Number of pixels & 28511 & 6983 & 84940 & 7924 \\
Area $\left(\mathrm{km}^{2}\right)$ & 1781.94 & 436.43 & 5308.75 & $495 \cdot 25$ \\
Minimum & 0 & -0.2449 & 0 & -0.2795 \\
Maximum & 0.6431 & 0 & 0.5268 & 0 \\
Mean & 0.0431 & -0.0168 & 0.0083 & -0.0125 \\
Standard deviation & 0.0483 & 0.0227 & 0.0099 & 0.0298 \\
\hline
\end{tabular}

a $\mathrm{OI}$, oasis regions with increasing trend.

${ }^{\mathrm{b}} \mathrm{OD}$, oasis regions with decreasing trend.

${ }^{\mathrm{c}}$ DI, desert regions with increasing trend.

${ }^{\mathrm{d}} \mathrm{DD}$, desert regions with decreasing trend.
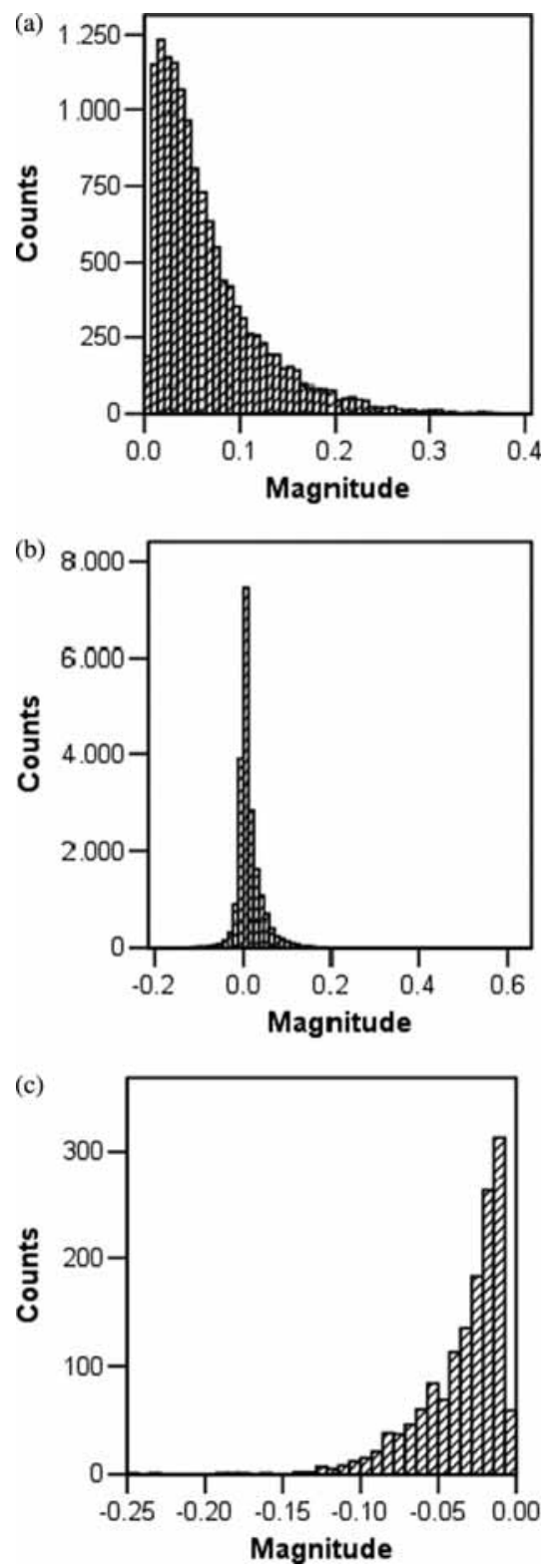

Figure 6. The trend magnitude distribution in oasis regions with (a) a statistically significant increasing trend; (b) no significant trend; and (c) a statistically significant decreasing trend

measures contained in the HEP, building artificial canals and river regulations were the most important measures and were commonly realized over the full extent of the

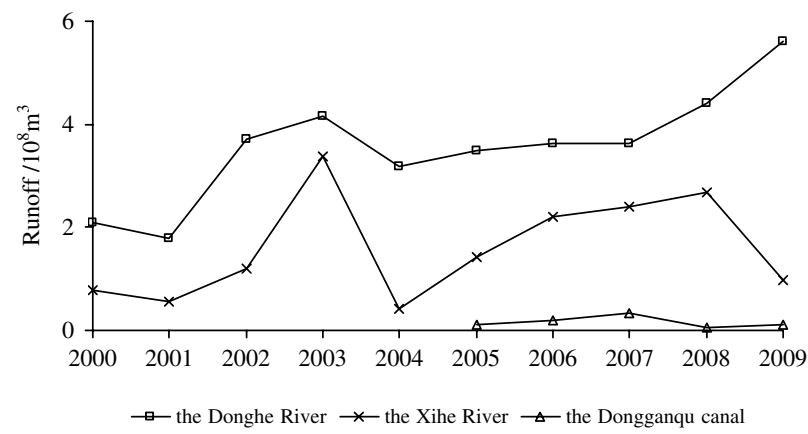

Figure 7. The runoff entering the Donghe River, the Xihe River, and the Dongganqu canal

Ejina basin. The canals and regulated rivers showed a relative higher flow velocity than the original natural rivers, which was beneficial for reducing both infiltration and evaporation losses in the upper and middle basin and increasing the surface runoff entering the lower basin. It was observed that the time period required for water to flow from the Langxinshan Diversion Structure to the Angcihe Diversion Structure has decreased from 5-7 days to $13 \mathrm{~h}$. From the Landsat images, it could be observed that many tributaries in the lower reaches of the Xihe River and the Donghe River resumed flowing during some periods every year. At the same time, it was observed during field investigations that the groundwater table increase and the vegetation growth at many locations were positively related to the runoff entering the Ejina basin (Guo et al., 2009). This indicated that the extensive vegetation recovery observed could attribute to comprehensive improvement of the water environment throughout basin, and this was the result of the joint action of the EWCP and HEP. However, spatial differences in the vegetation trend existed throughout the study region, raising the question of what the main causes of this heterogeneity were.

Vegetation trend in the Xihe River basin. In the Xihe River basin, engineering measures were implemented in the upper and middle regions and mainly included (1) regulating natural rivers or replacing them with artificial earth canals and (2) intercepting certain tributaries. From Quickbird images, it could be observed that the decreasing trend regions in the upper and middle Xihe 
River basin were mainly distributed near dried up tributaries, expect DZ1, which was located along a segment of artificial canals. It was also found that these regions were usually covered by woodlands. This indicated that (1) the scarcity of surface water in the intercepted tributaries had remarkably reduced the water supply for nearby vegetation and led to its degradation and (2) in most regions along the earth canals, the canal seepage had still effectively improved the nearby groundwater environment and advanced the growth of the natural vegetation. In the lower Xihe River basin, no engineering measures were taken, and the natural conditions were left as before. The vegetation degradation at some locations, such as DZ2 (Figure 5a), could be related to the local surface relief and groundwater flow field, which prevent current water environment improvements from meeting the requirements for local vegetation recovery. Wind erosion was another possible reason for this.

Vegetation trend in the Donghe River basin. Engineering measures were adopted throughout the Donghe River basin. In the upper and middle regions of this basin, the most important measure was the construction of the Dongganqu canal, which was designed to supersede the main channel of the Donghe River. However, this concrete-lined canal did not perform its expected functions and only carried a water volume of $0.83 \times 10^{8} \mathrm{~m}^{3}$ during 2000-2009, representing $1.5 \%$ of the total water entering the Ejina basin. In other words, the predominant role of the main channel of the Donghe River was not affected by engineering measures, and the increasing runoff enhanced the water environment, which generally improved the vegetation conditions nearby. Based on observations made during fieldwork, it was found that some locations showing vegetation degradation were located around incised river segments of the main channel. This implied that because of growing on high-altitude riverside regions, the vegetation scarcely benefited from the increasing groundwater level. Additionally, other types of vegetation degradation appeared at the gaps of vegetation belts along the rivers. These gaps came into being because the vegetation had completely degraded due to water scarcity in the past. Once the gaps formed, wind erosion considerably intensified at these sites, and it would be difficult for the vegetation to recover, even if the water environment improved. The Nalin River in the upper and middle Donghe River basin was the waterway most strongly affected by the construction of the Dongganqu canal. In the past, an independent shelterbelt had formed along the Nalin River and played an important role in preventing sandstorms. Considering its significance, the vegetation trend along the Nalin River has been specifically discussed in the following section.

A complex trend situation occurred in the lower Donghe River basin, which was not revealed in previous studies due to using regional mean data (Jin et al., 2008, 2010). As shown in Figure 5a, a pattern of alternating decreasing and increasing trend strips was observed in the lower Donghe River basin, where natural woodlands were dominant, which were mainly composed of P. euphratica and the T. ramosissiman, and some areas of cultivated lands existed. The streamflow is currently divided into several water channels by the Angcihe Diversion Structure when it arrives in the lower reaches of the Donghe River. Nine main water channels located around the Angcihe Diversion Structure in a clockwise direction are shown in Figure 1 and listed in Table III, among which the Yidao River (C2) was the only channel leading to East Juyan Lake. To accomplish the target of recovering the East Juyan Lake, the water volume in the Yidao River (C2) must be guaranteed. This implies that no or little water would pass through the other water channels in the case of insufficient streamflow entering the lower reaches of the Donghe River. As the Tiekuliganqu canal (C1), the Erdaoheganqu canal (C3), and the Sidaoheganqu canal (C5) were concrete-lined, they provided little surface water and groundwater for the regions along them except around the outlets of certain lateral canals. However, the Yidao River (C2) and the Sandao River (C4), which were two natural rivers meandering between $\mathrm{C} 1, \mathrm{C} 3$, and $\mathrm{C} 5$, could effectively improve nearby water environment through overflow and infiltration. This is the reason that the decreasing trend strips occurred on the left bank of the Tiekuliganqu canal (C1), the right bank of the Erdaoheganqu canal (C3), and the left bank of the Sidaoheganqu canal (C5), while the regions between them showed an increasing trend. Because the Sandao River (C4) did not receive as much water as the Yidao River (C2), its influence was less than that of the Yidao River (C2). Between the Sidaoheganqu canal (C5) and the Banbuerheganqu canal (C9), most regions showed a statistically significant increasing trend (Figure 5b). However, it should be noted that increasing trends with a magnitude greater than $0 \cdot 14 \mathrm{a}^{-1}$ resulted from cultivated land reclamation, not the recovery of natural vegetation.

Vegetation trend along the Nalin River. The Nalin River is the largest branch of the Donghe River in its upper and middle reaches, and it was cut off by the Dongganqu canal and completely dried up below the crosspoint after 2003 (Figure 1). Unlike the entirely decreasing trend situations observed around the intercepted tributaries of the Xihe River, both increasing and decreasing trends appeared along the Nalin River (Figure 5a). As previous field investigations have shown that the vegetation growth almost ceased beyond $1000 \mathrm{~m}$ from the water channels (Guo et al., 2009), we created a buffer at a distance of $1000 \mathrm{~m}$ around the segment below the crosspoint for detailed vegetation change analysis. Using Jenks natural breaks methods (Jenks, 1967) to analyse the SAN from $2000\left(\mathrm{SAN}_{2000}\right)$, the 597 pixels presenting significant trends at the $\alpha=0.05$ level in the oasis region within the buffer zone were grouped into four categories (Figure 8a and Table IV). Of these pixels, 32, or 5.4\%, were excluded from the discussion below because reclamation had taken place within them during 2000-2009 


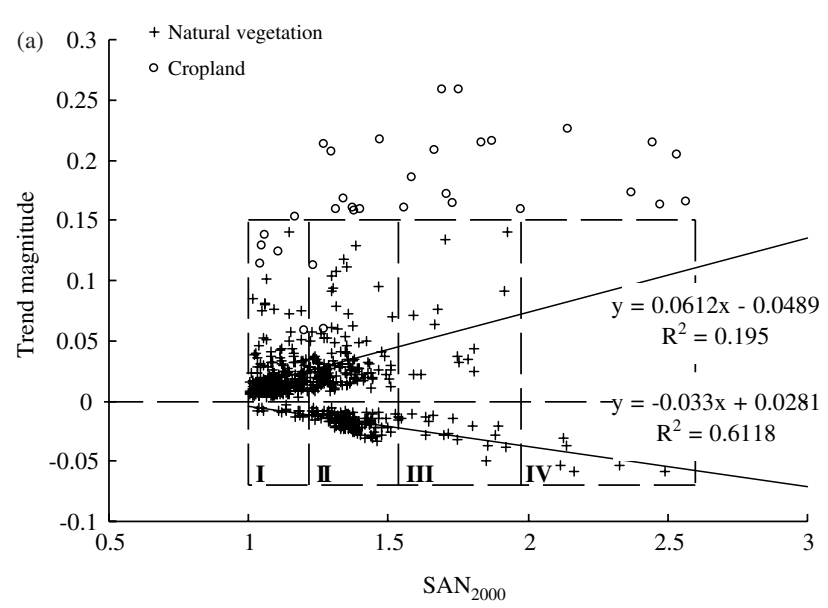

(b)

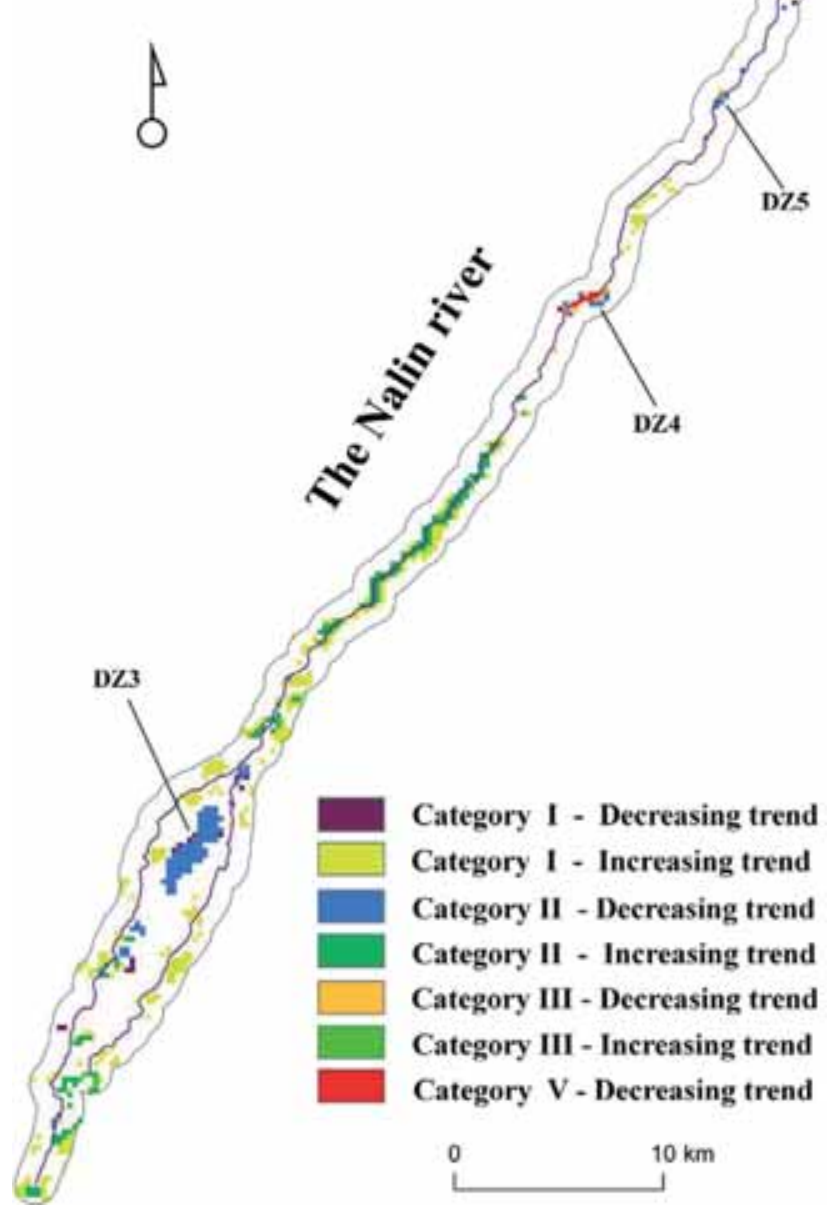

Figure 8. The $\mathrm{SAN}_{2000}$ distribution (a) and the spatial distribution of trend (b) of the pixels within the 1-km range around the Nalin River

(Figure 8a). For the remaining 565 pixels retaining natural vegetation, $289(51.1 \%)$ and $241(42.7 \%)$ were classified into Categories I and II, and only $29(5.1 \%)$ and 6 $(1.1 \%)$ were in Categories III and IV, respectively. With respect to their spatial distribution, the pixels in Categories II-IV mostly involved the river channels, except those with a declining trend in Category II, while the pixels in Category I were generally more than $100 \mathrm{~m}$ from the river channels. Based on the Quickbird images and
Table IV. Distribution of the $\mathrm{SAN}_{2000}$ and trend magnitude of the pixels within the 1-km range around the Nalin River

\begin{tabular}{lccr}
\hline Trend magnitude & -0.06 to 0 & 0 to 0.15 & $\sum$ \\
SAN $_{2000}$ & & & \\
\hline Category I $(1-1.214)$ & $15(5 \cdot 1 \%)$ & $274(94.9 \%)$ & 289 \\
Category II $(1.214-1.536)$ & $109(45.2 \%)$ & $132(54.8 \%)$ & 241 \\
Category III $(1.536-1.976)$ & $16(55 \cdot 2 \%)$ & $13(44.8 \%)$ & 29 \\
Category IV $(>1.976)$ & $6(100 \%)$ & & 6 \\
$\sum$ & $146(25 \cdot 8 \%)$ & $419(74.2 \%)$ & 565
\end{tabular}

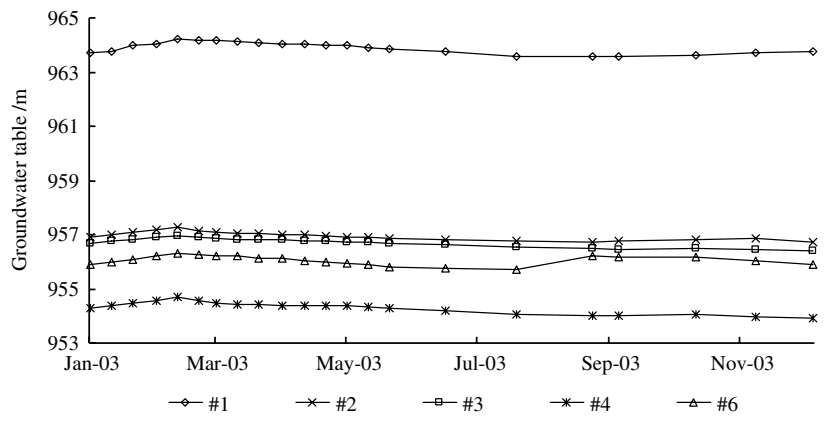

Figure 9. The groundwater table of \#1-4 and \#6 in 2003

field survey results, it could be observed that there were grasslands but scarcely any trees in the Category I pixels, and the proportion of the woodlands in the pixels increased from $20 \%$ in Category II to $90 \%$ in Category IV. This implied that the SAN value of the pixels in Category II-IV depended on the woodland condition.

Overall, $74.2 \%$ of the pixels showed an increasing trend, and $25.8 \%$ presented a decreasing trend (Table IV). However, the proportion of pixels presenting an increasing versus decreasing trend was reversed from Category I to IV: $94.9 \%$ of the pixels in Category I showed increasing trend; the number of pixels with increasing and decreasing trends was approximately equal in Categories II and III; and all pixels in Category IV presented a decreasing trend (Table IV). The regions with an increasing trend were mainly composed of the pixels in Categories I and II, for which there was no statistically significant relationship between the $\mathrm{SAN}_{2000}$ and trend magnitude (Figure 8a). Some pixels in Categories I and II in 2000 had transitioned into Categories II and III in 2009. The observed vegetation recovery indicated that the groundwater environment had improved, although the river runoff had dried up and could not recharge the groundwater. According to the groundwater table measured at wells \#1-4 and 6 (Figure 4), the groundwater table declined from both the Donghe River and the Xihe River to the Nalin River (Figure 9). This meant that with the runoff increasing in the Donghe River and the Xihe River and the groundwater table rising alongside them, the groundwater table along the Nalin River could also increase through groundwater flow. Additionally, the groundwater flow could come from the region above the crosspoint, which could still be reached by surface runoff and which exhibited a relatively high groundwater table due to recharging. 
As shown in Figures $5 \mathrm{a}$ and $8 \mathrm{~b}$, decreasing trends mainly occurred in the regions of DZ3, DZ4, and DZ5. DZ3 included more than $90 \%$ of the pixels with a decreasing trend in Category II. Although it was generally beyond $1000 \mathrm{~m}$ from the river channels, DZ3 was located in a floodplain where the woodlands covered, which was clear in the Quickbird images. With the water reduction in the Nalin River, this region was no longer submerged by surface water, which led to forest degradation. All of the pixels in DZ3 had downgraded into Category I in 2009. In contrast to, DZ3 which was almost completely composed of pixels in Category II, DZ4 and DZ5 showed a ring-shaped structure with multiple bands around watercourses. The pixels included in the bands varied from Category IV to II for the bands far away from the watercourse. As shown in Figure 8a, there was a significant negative relationship between the $\mathrm{SAN}_{2000}$ and the trend magnitude for the pixels with a decreasing trend, which indicated that the better the woodland status in 2000, the more severe was the degradation that occurred. The pixels in Categories IV and III in DZ4 and DZ5 had degraded to the Categories III and II in 2009, respectively. The possible reason for this was that the trees in high-SAN regions had relatively shallower root systems than those in low-SAN regions because they were closer to the river channels and always enjoyed a better water environment. When the water environment suddenly deteriorated with the disappearance of surface water, the shallow-rooted vegetation had a weaker ability to rapidly adapt or survive. The woodland degradation along the Nalin River has attracted local residents' attention. A similar situation also occurred in the lower Donghe River basin, such as in DZ6 and DZ7 (Figure 5a), where some natural tributaries had always passed through previously but are currently completely dried up.

\section{Vegetation change in desert regions}

The vegetation change in desert areas, especially in the Gobi, has often been ignored in the literature because of its low densities, but it plays an important role in ecosystem protection, as dust storms are prone to happen in the Gobi (Parungo et al., 1994; Wang et al., 2004). For the purpose of studying, the vegetation trend in desert regions, the stable desert regions, and the desert-to-oasis regions were combined as one category encompassing approximately $5804 \mathrm{~km}^{2}$.

Because there is almost no surface water in most of the desert regions, the plant growth there almost completely depended on the groundwater environment, including the groundwater table depth and salinity. Generally, the plants in desert regions are characterized by a deep root system, which ensures the survival of the vegetation, even if the groundwater table is found at considerable depth. For example, N. tangutorum Bobr and $H$. ammodendron, two predominant plant species in the desert regions of the Ejina basin, can extend their roots to approximately $3-13 \mathrm{~m}$ and $4-5 \mathrm{~m}$ below the ground, respectively. Previous field studies have found that approximately $2-4 \mathrm{~m}$ is the range of the functional groundwater table depth for desert vegetation functioning (Chen 2004; Chen et al., 2008). From 2001 to 2009, the groundwater table depth was measured at 11 observation wells (Figure 4). The wells located in desert regions, \#2, \#3, \#5, and \#7-11, exhibited a groundwater table depth that fluctuated between 2.11 and $3.79 \mathrm{~m}$. These meant that the groundwater environment changes taking place were able to influence the growth of desert vegetation, at least in many locations, if not in whole regions.

An increasing trend of the SAN was found from 2000 to 2009 for $5309 \mathrm{~km}^{2}$, or $91.5 \%$ of the desert regions, and the increasing trend was statistically significant at the $\alpha=0.05$ level for $1538.9 \mathrm{~km}^{2}$, or $26.5 \%$; while $495 \mathrm{~km}^{2}$, or $8.5 \%$, of the desert regions showed a decreasing trend, with $61.2 \mathrm{~km}^{2}$, or $1.1 \%$, of this area exhibiting statistical significant at the $\alpha=0.05$ level (Figure 10a and $\mathrm{b}$ ). The mean trend magnitudes of the SAN were 0.0083 and $-0.0125 \mathrm{a}^{-1}$ for the increasing and decreasing trend regions, respectively (Table III). The significant increasing trend of the SAN appeared over large areas along or between the water channels in the middle and lower Xihe River basin and at the oasis periphery in the lower Donghe River basin (Figure 10b). The SAN trend magnitude in the regions with a statistically significant increase varied from 0.001 to $0.5268 \mathrm{a}^{-1}$ (Table III and Figure 11a) and could be divided into two categories. There were $43.2 \mathrm{~km}^{2}$, or $2.8 \%$, of the regions associated with a statistically significant increase, showing a magnitude greater than $0.05 \mathrm{a}^{-1}$. They were mainly distributed around the East Juyan Lake and the lowlands over the middle and lower Xihe River basin, where transient lakes were easily formed (Figure 10b). The magnitude was especially large around the East Juyan Lake, being greater than 0.2 $\mathrm{a}^{-1}$. The local inhabitants and government confirmed the improvement of the $H$. ammodendron communities in the lower Ejina basin. The remaining $97.2 \%$ of the regions showed a trend magnitude of $0.001-0.05 \mathrm{a}^{-1}$, and the trend magnitudes around the outlets of canals were generally greater than those along the canals. All these findings indicated that vegetation being nourished or irrigated by surface water is expected to be much more vigorous than that only depending on groundwater. The conversion from desert to oasis mainly took place in areas where surface water appears readily, such as at the outlets of artificial canals, natural riversides and low elevation locations.

Although the minimum trend magnitude in the decreasing SAN regions was as low as $-0.2795 \mathrm{a}^{-1}$ (Table III), the regions with a trend magnitude less than $-0.05 \mathrm{a}^{-1}$ only occupied $19.5 \mathrm{~km}^{2}$, or $3.93 \%$, of the decreasing trend regions (Figure $11 \mathrm{~b}$ and $\mathrm{c}$ ), and these occurred almost entirely around the East Juyan Lake (Figure 10a). Because the East Juyan Lake maintained a surface area greater than $20 \mathrm{~km}^{2}$ after 2002, the steep decreasing trend of the SAN in this region reflected the change in the water body, not the vegetation. The regions associated with a magnitude between -0.05 and $-0.005 \mathrm{a}^{-1}$, 
(a)

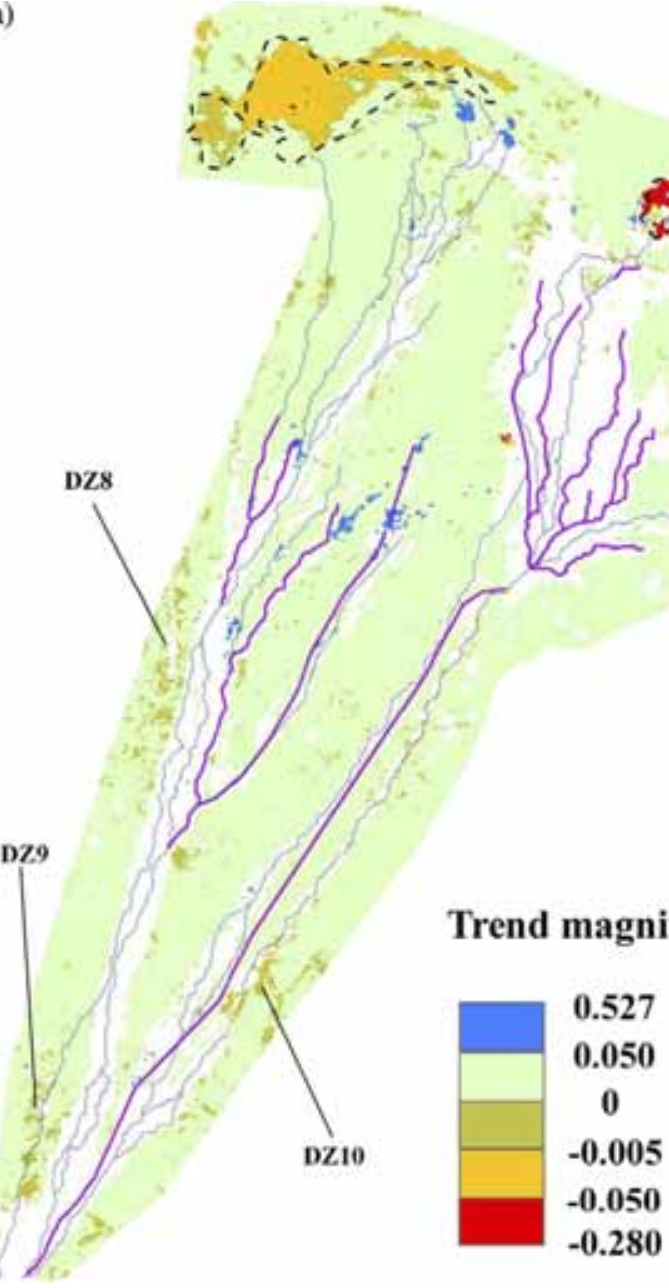

(b)

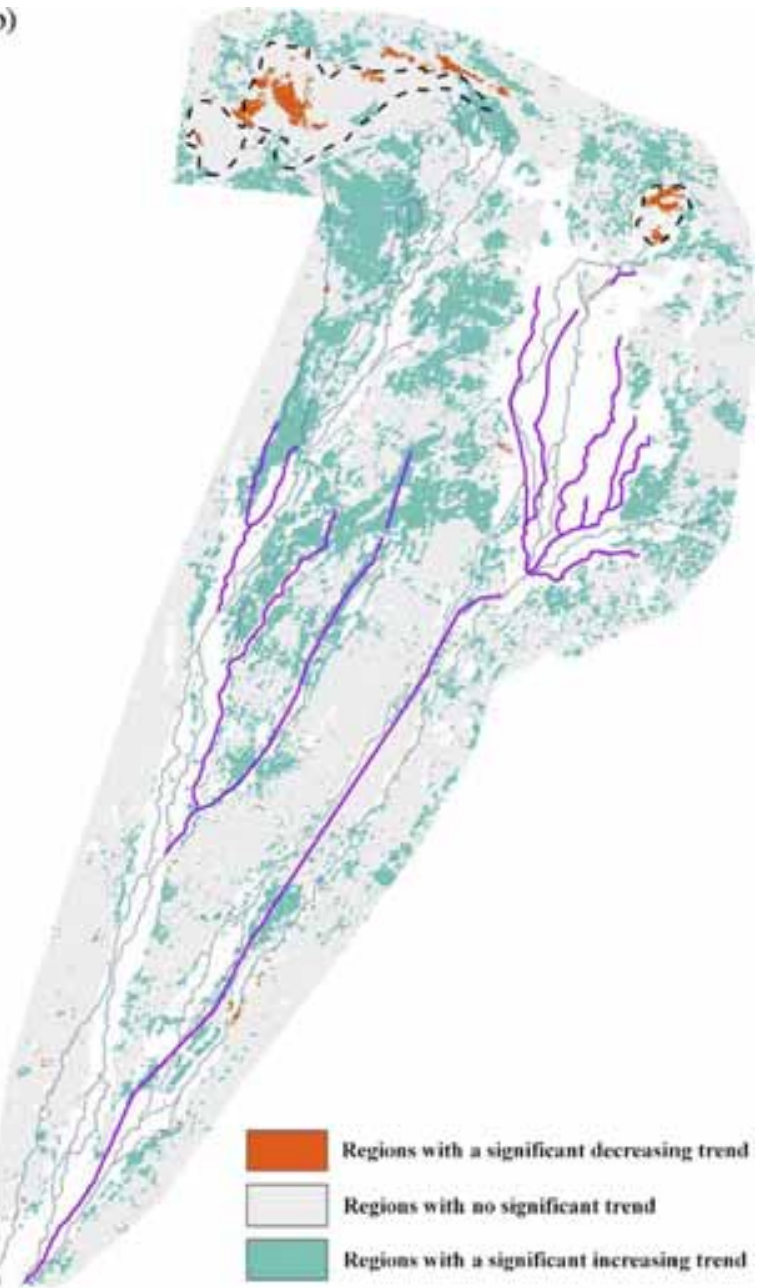

Figure 10. Vegetation trend in desert regions: (a) spatial distribution of trend magnitude and (b) the results of significance tests at $\alpha=0.05$. (DZ, decreasing trend zone)

representing approximately $180.9 \mathrm{~km}^{2}$, or $36 \cdot 5 \%$, of the decreasing trend regions, were mainly located in the West Juyan Lake, and the magnitude was observed to increase with the distance from the lake centre. The West Juyan Lake exhibited a dried up condition most of the time after 2000 because few streamflow reached this area. However, as this was an area associated with groundwater discharge (Xie, 1980), its groundwater table was relatively high. Due to strong evaporation, the salinity continually accumulated in the lake basin and further constrained the growth of vegetation. Thus, the decreasing trend in this region most likely indicates the change of surface salinity and is irrelevant to the vegetation change. The remaining regions associated with a magnitude of less than $-0.005 \mathrm{a}^{-1}$, representing approximately $294.9 \mathrm{~km}^{2}$, or $59.5 \%$, of the decreasing trend regions, were sporadically distributed along several rivers and presented vegetation degradation. DZ8, DZ9, and DZ10 were three zones where decreasing trend pixels were concentrated. DZ8 and DZ9 were located along the Balajieraobao River, which was a tributary of the Xihe River (Figure 1) that has been dried up for several years. DZ10 was situated beside a region of degraded oasis along the Donghe River (Figure 5a), and the vegetation degradation observed there may also have been due to the altitude gap between the riverside and the watercourse, as mentioned above. As shown in Figure 10b, statistically significant decreasing trends appeared in nearly all regions of two terminal lakes where the arid Gobi had been converted into lake or salina, but in scarcely any of the regions with sparse vegetation coverage. Thus, the degradation of the desert vegetation was not statistically significant in the study area.

\section{Succession of the plant community involved in vegetation change}

The vegetation change involved changes not only in the coverage and vigour of plants but also in the succession of plant community. Previous field studies in the study region have found that the species diversity of plants has increased and benign succession has occurred, such that low-quality species (e.g. S. alopecuroides $L$ and Alhagi sparsifolia) in forests have been superseded by highquality species (e.g. Radix glycyrrhiza and Achnatherum splendens) in some locations (Jiang and Liu, 2009). The rejuvenation of the $P$. euphratica forests has been widely reported, and the appearance of seedlings has been considered the most important symbol of the recovery of the 

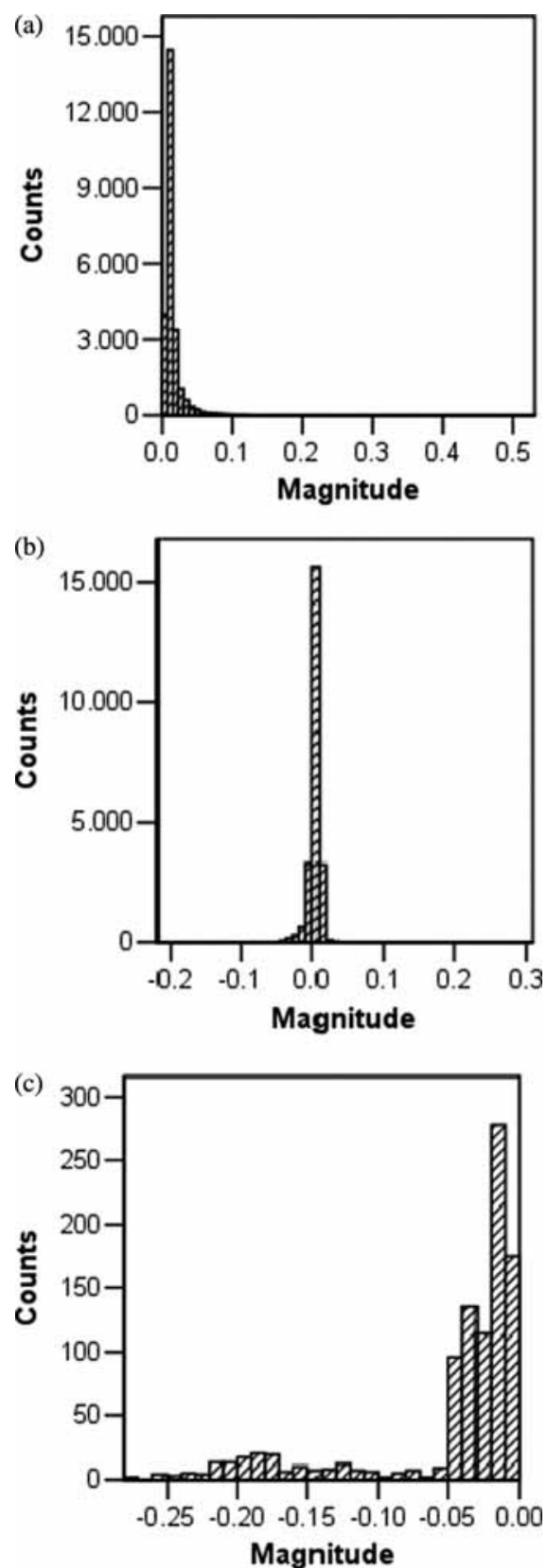

Figure 11. The trend magnitude distribution in desert regions with (a) a statistically significant increasing trend; (b) no significant trend; and (c) a statistically significant decreasing trend

forests. However, further field investigations at several locations showed that the percentage of young trees in the forests was still low, and the forests were declining in terms of population structure (Li et al., 2008). Additionally, because of the asynchronism between surface runoff and seed germination, the natural reproduction of the $P$. euphratica forest was found to generally be occurring through root suckers, not seeds, indicating that it was difficult for the original forest type to return. This suggested that the increasing trend of the SAN of the $P$. euphratica forests had mainly resulted from the rejuvenation of mature trees and did not represent the population returning to a positive life cycle. As mentioned above, the observed vegetation degradation mostly took place in woodlands, which play the principal role in preventing sandstorms. Once gaps formed in the forest belts due to the development of degradation, the intensity of wind erosion on the forests increased considerably and resulted in degradation directly to desert, passing over the intermediate landscape of shrubs and grasslands. All the above observations indicated there were complex biological processes and ecological interactions occurring throughout the study region. Therefore, there is an urgent need to evaluate the potential impact of current spatial and biological features of vegetation change on the whole ecological system, which represents the foundation for the establishment of future basin management strategies. Because it is difficult to detect plant community changes with remote sensing technology at present, additional field studies integrating hydrological, biological, and ecological measures were required.

\section{General evaluation of the impacts of the integrated water management}

In the past 10 years, the recovery of the vegetation throughout the Ejina basin and the East Juyan Lake has been two explicit objectives of the integrated water management measures that have been undertaken. The measures included in the HEP have fully embodied this intention. The distribution of the main canals and lateral canals was carefully designed, which has made it possible for the water environment in almost all of the oasis regions and partial desert regions to rapidly improve. However, there was a great gap between the results and the expectations in terms of vegetation recovery: the vegetation degradation has continued in many oasis regions, especially along the Nalin River and in the lower Donghe River basin. As mentioned above, the observed vegetation degradation was generally caused by the fact that nearby rivers were cut off or replaced by artificial main canals. It was planned that these vegetated regions would be irrigated through the lateral channels extending from the main canals. For example, the oasis along the Nalin River would be irrigated through the lateral canals extending from the Dongganqu canal. However, in reality, the irrigation was not carried out satisfactorily because the main canals often carried insufficient amounts of water. The water scarcity in the Dongganqu canal was mainly due to civil engineering problems that constrained its discharge, while the water insufficiency in the main canals in the lower Donghe River basin mainly resulted from water allocation that was closely related to another objective, namely the recovery of the East Juyan Lake. To recover the East Juyan Lake, a great deal of the runoff arriving in the lower Donghe River basin was allocated to the Yidao River and rapidly entered the East Juyan Lake. Since 2002, the water volume infused into the lake has been greater than $3.1 \times 10^{8} \mathrm{~m}^{3}$. As a consequence, the East Juyan Lake has maintained a surface area of greater than $20 \mathrm{~km}^{2}$, whereas many canals in the lower Donghe River basin have received little water. Because the East Juyan Lake was the lowest area of 
the Ejina basin, the water in lake was incapable of contributing to the improvement of the water environment at other locations in the basin, except around the lake itself. Eventually, all of the water in lake was lost through evaporation. Therefore, it is worth discussing the necessity of recovering the East Juyan Lake. Reducing the water allocated to the Yidao River and increasing the water to other canals should be more beneficial to restoration of the ecological environment in the lower Donghe River basin.

\section{CONCLUSIONS}

In this study, multi-temporal and multi-scale remotely sensed data and field investigations were used to study the vegetation responses to the implementation of integrated water management measures in the Ejina basin, northwest China. The results showed that the stable oasis regions and stable desert regions represented approximately 2131 and $5308 \mathrm{~km}^{2}$ of the study region, respectively, and the conversion from oasis to desert or vice versa occurred in approximately 87 and $496 \mathrm{~km}^{2}$ of the study area, respectively. The vegetation in $80.4 \%$ of the oasis and $91.5 \%$ of the desert regions showed a positive changing trend of the SAN from 2000 to 2009 , specifically related to vegetation rejuvenation or recovery. The statistically significant increasing trend of desert vegetation mainly appeared in the middle and lower Xihe River basin and the lower Donghe River basin. The locations where surface water could arrive, such as the outlets of artificial canals and the banks of natural rivers, usually showed larger trend magnitudes of the SAN than other regions, and the conversion from desert to oasis commonly took place in these regions. However, it should be noted that increasing SAN trend magnitudes greater than $0.14 \mathrm{a}^{-1}$ mainly resulted from cultivated land reclamation, not from considerable natural vegetation rejuvenation or recovery. At the same time, the vegetation in $19.6 \%$ of the oasis and $5.1 \%$ of the desert regions presented a negative SAN trend related to nearby surface water reduction, specifically associated with vegetation degradation, which generally took place along artificial canals and intercepted rivers. Along the natural rivers experiencing water reduction, such as the Nalin River, opposite vegetation trend signs could be observed simultaneously: the decreasing trends generally appearing at regions with a high SAN, representing woodland degradation, while the increasing trend appearing in the low SAN regions, indicating grassland restoration. Underlying the SAN change were changes not only in the coverage and vigour of vegetation but also in the succession of the plant community. These complicated biological and ecological processes require further investigation.

As the implementation of vegetation protection countermeasures has ensured natural conditions for vegetation growth, the vegetation recovery and degradation have depended on the spatial pattern of water environment changes in the study region. The broad vegetation recovery observed was due to the comprehensive improvement of the water environment, which should be attributed to both the increase in runoff entering the Ejina basin and the guidelines of the integrated water management measures aiming at making the rivers flow downstream as far as possible. To realize this goal, many engineering measures have been implemented, such as building artificial canals, river regulations, and intercepting tributaries. These engineering measures have increased the runoff flowing to the lower Ejina basin, but they have simultaneously caused water environment deterioration at many locations because of unexpected water allocation and further resulted in vegetation degradation these areas. As an objective of the integrated water management measures, the recovery of the East Juyan Lake has been achieved, but its necessity should be given serious consideration due to its negative impact on the vegetation in the lower Donghe River basin. Given the very limited amounts of runoff flowing into the Ejina basin at present, integrated water management is the only solution for ecosystem recovery. However, how to manage the limited water resources in the region and achieve the optimization of the recovery of the whole ecological environment is becoming a highly challenging issue, and the results of this study can be used as a reference for water resource planning and management to maintain healthy and proper functioning of the river as well as for regional development.

\section{ACKNOWLEDGEMENTS}

This research was supported by the National Basic Research Program of China (973 Program; No. 2009CB421305) and the National Natural Science Foundation of China (Nos 40901024 and 40701050). The authors are grateful to Associate Professor Baolin Li of the Institute of Geographical Science and Natural Resources Research of the Chinese Academy of Sciences for his invaluable advices and to Leilei Min, Runliu Song, and Fei Ao for their participation in the field work.

\section{REFERENCES}

Chappell A, Seaquist JW, Eklundh L. 2001. Improving the estimation of noise from NOAA AVHRR NDVI for Africa using geostatistics. International Journal of Remote Sensing 22: 1067-1080.

Chen YN. 2004. Physiological response of natural plants to the change of groundwater level in the lower reaches of Tarim River,Xinjiang. Progress in Natural Science 14: 975-983.

Chen YN, Chen YP, Xu CC, Ye ZX, Li ZQ, Zhu CG, Ma XD. 2010. Effects of ecological water conveyance on groundwater dynamics and riparian vegetation in the lower reaches of Tarim River, China. Hydrological Processes 24: 170-177.

Chen YN, Pang Z, Chen Y, Li W, Xu C, Hao X, Huang X, Huang T, Ye Z. 2008. Response of riparian vegetation to water-table changes in the lower reaches of Tarim River, Xinjiang Uygur, China. Hydrogeology Journal 16: 1371-1379.

Coppin P, Jonckheere I, Nackaerts K, Muys B, Lambin E. 2004. Digital change detection methods in ecosystem monitoring: a review. International Journal of Remote Sensing 25: 1565-1596.

Fabricante I, Oesterheld M, Paruelo JM. 2009. Annual and seasonal variation of NDVI explained by current and previous precipitation across Northern Patagonia. Journal of Arid Environments 73: 745-753. 
Feng Q, Cheng GD. 1998. Current situation, problems and rational utilization of water resources in arid north-western China. Journal of Arid Environments 40: 373-382.

Feng Q, Wei L, Su YH, Zhang YW, Si JH. 2004. Distribution and evolution of water chemistry in Heihe River Basin. Environ Geol 45: 947-956.

Fu GB, Charles SP, Yu JJ, Liu CM. 2009a. Decadal climatic variability, trends and future scenarios for the North China Plain. Journal of Climate 22(8): 2111-2123.

Guo QL, Feng Q, Li JL. 2009. Environmental changes after ecological water conveyance in the lower reaches of Heihe River, northwest China. Environmental Geology 58: 1387-1396.

Hansen MC, Roy D, Lindquist E, Justice CO, Altstatt A. 2008. A method for integrating MODIS and Landsat data for systematic monitoring of forest cover and change in the Congo Basin. Remote Sensing of Environment 112: 2495-2513.

Herrmann SM, Anyamba A, Tucker CJ. 2005. Recent trends in vegetation dynamics in the African Sahel and their relationship to climate. Global Environmental Change 5: 394-404.

Hipel KW, McLeod AI. 2005. Time Series Modelling of Water Resources and Environmental Systems. Electronic reprint of our book originally published in 1994. http://www.stats.uwo.ca/faculty/aim/1994Book/.

Hirsch RM, Slack JR, Smith RA. 1982. Techniques of trend analysis for monthly water quality data. Water Resources Research 18: 107-121.

Jarlan L, Mangiarotti S, Mougin E, Mazzega P, Hiernaux P, Le Dantec V. 2008. Assimilation of SPOT/VEGETATION NDVI data into a sahelian vegetation dynamics model. Remote Sensing of Environment 112: $1381-1394$.

Jenks GF. 1967. The data model concept in statistical mapping. International Yearbook of Cartography 7: 186-190.

Ji XB, Kang ES, Chen RS, Zhao WZ, Zhang ZH, Jin BW. 2006. The impact of the development of water resources on environment in Arid Inland River basins of Hexi region, Northwestern China. Environmental Geology 50: 793-801.

Jiang XH, Liu CM. 2009. The response of vegetation to water transport in the lower reaches of the Heihe River. Acta Geographica Sinica 64(7): $791-797$ (in Chinese)

Jin XM, Hu GC, Li WM. 2008. Hysteresis effect of runoff of the Heihe River on vegetation cover in the Ejina oasis in northwestern China. Earth Science Frontiers 15(4): 198-203.

Jin XM, Schaepman M, Clevers J, Su ZB, Hu GC. 2010. Correlation between annual runoff in the Heihe River to the vegetation cover in the Ejina Oasis. Arid Land Research and Management 24: 31-41.

Li J, Zhang QL, Gao RH, Lu P. 2008. Study on the population structure and distribution pattern of Populus euphratica populations in Ejina Oasis. Journal of Arid Land Resources and Environment 22(2): 187-190 (in Chinese).
Mann HB. 1945. Nonparametric tests against trend. Econometrica 13 245-259.

McGwire K, Minor T, Fenstermaker L. 2000. Hyperspectral mixture modeling for quantifying sparse vegetation cover in arid environments. Remote Sensing of Environment 72: 360-374.

Neigh CSR, Tucker CJ, Townshend JRG. 2008. North American vegetation dynamics observed with multi-resolution satellite data Remote Sensing of Environment 112: 1749-1772.

Olsson L, Eklundh L, Ardö J. 2005. A recent greening of the Sahel-trends, patterns and potential causes. Journal of Arid Environments 63: 556-566.

Parungo F, Li Z, Li X, Yang D. 1994. Gobi dust storms and the Great Green Wall. Geophysical Research Letters 21: 999-1002.

Pouliot D, Latifovic R, Olthof I. 2009. Trends in vegetation NDVI from $1 \mathrm{~km}$ AVHRR data over Canada for the period 1985-2006. International Journal of Remote Sensing 30(1): 149-168.

Qi SZ, Luo F. 2005. Water environmental degradation of the Heihe River basin in arid northwestern china. Environmental Monitoring and Assessment 108: 205-215.

Sen PK. 1968. Estimates of the regression coefficient based on Kendall's tau. Journal of American Statistical Association 63: 1379-1389.

Sun ZY, Xu HL. 2008. Landscape pattern evolution and its ecological mechanism in Ejina Basin from 1977 to 2005. Journal of Arid Land Resources and Environment 22(10): 187-190 (in Chinese).

Wang GX, Cheng GD. 1999. Water resource development and its influence on the environment in arid areas of China-the case of the Hei River basin. Journal of Arid Environments 43: 121-131.

Wang XM, Dong ZB, Zhang JW, Liu LC. 2004. Modern dust storms in China: an overview. Journal of Arid Environments 58: 559-574.

Xi HY, Feng Q, Liu W, Si JH, Chang Z, Su Y. 2009. The research of groundwater flow model in Ejina Basin, northwest China. Environmental Earth Sciences DOI: 10.1007/s12665-009-0231-1 (published online)

Xie Q. 1980. Regional hydrogeological survey report of the People's Republic of China (1:200 000): Ejina K-47-[24] [R], Jiuquan (in Chinese).

Xu ZM, Cheng GD, Zhang ZQ, Su ZY, Loomis J. 2003. Applying contingent valuation in China to measure the total economic value of restoring ecosystem services in Ejina region. Ecological Economics 44: $345-358$.

Zhang XY, Gong JD, Zhao X, Zhou MX. 2005. The change of land cover/land use in Ejina oasis over 20 years. Advanced Earth Sciences 20(12): 1300-1305.

Zhu YH, Ren LL, Skaggs TH, Lü HS, Yu ZB, Wu YQ. 2009. Simulation of Populus euphratica root uptake of groundwater in an arid woodland of the Ejina Basin, China. Hydrological Processes 23: 2460-2469. 